\title{
A História da Mastologia no Inca
}

\author{
History of the Breast Cancer Clinic at Inca
}

Pedro Aurélio Ormonde do Carmo ${ }^{1}$, João Luiz Campos Soares² Sergio Ré de Paiva ${ }^{3}$ e Darcy da Silva Guimarães ${ }^{4}$

\author{
${ }^{1}$ M édico-M astologista; Diretor do H ospital do Câncer III do IN CA. \\ ${ }^{2}$ M édico-M astologista - Ex-Chefe da Seção de M astologia do IN CA \\ ${ }^{3}$ Biólogo-Ex-Coordenador do Laboratório Central de Citopatologia do HC III do IN CA \\ ${ }^{4}$ Assessor da Direção Geral do IN CA
}

Com o aumento progressivo da mortalidade por doenças crônicodegenerativas, entre elas o câncer, houve na década de 30, uma reorientação da política nacional de saúde.

Em 13 de janeiro de 1937, o então presidente G etúlio Vargas assinou o D ecreto Lei 378, que criou um Centro de C ancerologia no Rio de Janeiro. Este Centro foi inaugurado em 1938 no H ospital Estácio de Sá (hoje Hospital da Polícia M ilitar do Rio de Janeiro), com 40 leitos, um bloco cirúrgico, um aparelho de radiodiagnóstico e um de radioterapia, tendo como seu diretor o professor Mário Kröeff, um dos pioneiros na pesquisa e no tratamento do câncer no Brasil.

Em 1939, pelo Decreto Lei № 1.040, 0 referido Centro ficou sob responsabilidade da Prefeitura do Distrito Federal.

Já em 1941, pelo Decreto Lei no 3.643, foi criado o Serviço N acional de Câncer SN C, cuja responsabilidade foi outorgada ao Prof. Mário Kröeff. O Serviço passou a funcionar nas dependências do Centro de Cancerologia e teve como seu colaborador principal o médico Alberto Lima de M oraes Coutinho. Esses dois médicos tinham como tarefa propor uma política nacional de controle do câncer.

No dia 4 de julho de 1944, através do D ecreto 15.971, foi aprovado o regimento do Serviço $N$ acional de $C$ âncer que, em seu artigo $2^{\circ}$, oficializava a criação do Instituto de Câncer, órgão executivo do Serviço $\mathrm{N}$ acional de Câncer.

Em 1946, o Serviço N acional de Câncer foi transferido para o H ospital Gaffréee Guinle, onde havia melhores condições de funcionamento. N essa época e até 1952, não havia equipes especializadas. 0 s médicos eram formados, na sua maioria, por cirurgiões gerais provenientes do Serviço de Cirurgia do Prof. Brandão Filho, da Faculdade de M edicina do Brasil, hoje Universidade Federal do Rio de Janeiro, e as intervenções eram realizadas indistintamente por todos.

Com a progressiva incorporação dos avanços técnico-científicos e crescimento do Serviço, impôs-se a criação de seções especializadas, iniciativa esta que foi implantada a partir de 1956. As doentes de tumores de mama, no entanto, continuavam sendo atendidas por qualquer uma das seções especializadas criadas, já que inexistia uma especificamente dedicada a isso.

A já elevada freqüência e a incidência cada vez maior das afecções mamárias justificavam a existência de uma equipe especializada, visando a um melhor atendimento às enfermas e melhores possibilidades de estudo do câncer mamário.

Em 1957, ocorreu a inauguração oficial da nova sede do Instituto de $C$ âncer na Praça da C ruz Vermelha, tendo como diretor 0 médico Antônio Pinto Vieira e, como diretor 
do Serviço Nacional de Câncer, o Prof. U go de $C$ astro Pinheiro Guimarães. 0 Instituto já dispunha de quase todas as seções especializadas, exceto a de M astologia e a de Cirurgia de Tecido Ó sseo. E foi neste mesmo ano de 1957 que, no dia 01 de abril, criou-se a Seção de M astologia sendo o seu primeiro chefe 0 médico Alberto Lima de M oraes Coutinho, que a liderou de 1957 a 1967. 0 Dr. Coutinho formou a primeira equipe com os médicos João Luiz Campos Soares e Clóvis Fraga de Andrade. Também passaram a integrar essa equipe os internos acadêmicos, Agostinho do Passo e Nelson Augusto Rodrigues.

Alberto Lima de M oraes Coutinho foi 0 pioneiro da Mastologia brasileira. Com o intuito de divulgar as mais recentes pesquisas nesta especialidade, organizou vários cursos no Rio de Janeiro e em outros estados federativos. No dia 03 de julho de 1959, ao término de um curso realizado no Instituto de $C$ âncer, que teve como intenção arregimentar novos companheiros, o Dr. Alberto fundou a Sociedade Brasileira de Patologia M amária, hoje Sociedade Brasileira de M astologia, da qual foi presidente por três vezes.

A atuação de Alberto Lima de M oraes Coutinho culminou com o reconhecimento da $M$ astologia pela Associação $M$ édica B rasileira, no dia 28 de janeiro de 1978 , como especialidade médica, nascida que foi no Instituto de Câncer,

Pelo D ecreto 50.251, de 28 de janeiro de 1961, o Instituto de Câncer passou a denominar-se Instituto $\mathrm{N}$ acional de $\mathrm{C}$ âncer, para o qual foram atribuídas novas competências nos campos assistencial, científico e educacional.

Em 1965, durante a direção do Prof. Francisco Fialho, houve a fusão das seções especializadas de $M$ ama e Ginecologia, sob a chefia de Alberto Coutinho. Este novo sistema perdurou por cerca de dois anos e, em maio de 1967, as especialidades voltaram a ter seções independentes.

Por ato do então M inistro de Estado da Saúde, Leonel M iranda, o Instituto $\mathrm{N}$ acional de Câncer foi, em maio de 1969, desligado do M inistério da Saúde, passando para a administração da Fundação Escola de M edicina e Cirurgia do Rio de Janeiro, entidade ligada ao M inistério da Educação e Cultura. Este fato muito contribuiu para 0 esvaziamento funcional do Instituto. Por discordarem dessa determinação, Jorge Sampaio de M arsillac M otta, então diretor do Instituto Nacional de Câncer, e Alberto Lima de M oraes Coutinho saíram do IN CA. D e maio de 1969 a 31 de dezembro de 1971, as seções de M astologia e de $G$ inecologia foram chefiadas pelo Prof. 0 smar Teixeira Costa, designado pelo Diretor da Faculdade, Professor Cláudio G oulart de Andrade. M as, no dia 01 de janeiro de 1972, o Instituto $\mathrm{N}$ acional de Câncer, através da Lei no 5.734 , de 16 de novembro de 1971, reintegrou-se ao M inistério da Saúde.

Em virtude da designação de Alberto Lima de M oraes C outinho para a chefia da D ivisão de M edicina e Cirurgia, constante do Regimento do Instituto Nacional de Câncer, assumiu a chefia da Seção de M astologia o médico João Luiz Campos Soares.

Desde a sua criação, a Seção de M astologia do IN CA tevea sua chefia ocupada pelos seguintes médicos: Alberto Lima de M oraes C outinho (1952-1967), J oão Luiz C ampos Soares (I967-1983 e 1984-1991), N ey D uque Estrada (1983-1984) e Pedro Aurélio O rmonde do Carmo (1991-1999).

Porém, em 1992, com reformulação orientada pela Lei O rgânica da Saúde, a 8080/ 90, que criou o SUS, dois novos hospitais haviam sido incorporados ao IN CA: o H ospital de 0 ncologia/Inamps e o Centro de Ginecologia Luíza G omes de Lemos/Fundação das Pioneiras Sociais. Com isso, além daquela liderada por Pedro Aurélio, no agora H ospital de Câncer I (assim estabelecido no novo regimento do M inistério da Saúde, pelo D ecreto 2.477, de 28 de janeiro de 1998), 0 I N C A passou a contar com mais duas outras seções de M astologia.

Também, a partir dessa incorporação, as histórias desses dois hospitais passaram a compor a história do IN CA:

\section{O Hospital de Oncologia (Hospital de Câncer II do INCA)}

O casal Mathilde e Firmino Von D ollinger da Graça foram os grandes 
colaboradores para a criação do H ospital de $\mathrm{O}$ ncologia. $\mathrm{O}$ nome de $\mathrm{M}$ athildefoi dado ao prédio, ainda em construção, em gratidão ao trabalho desenvolvido por ela e por seu marido. As terras foram doadas pelo então presidente Getúlio Vargas para 0 Instituto Brasileiro de O ncologia (IBO), uma entidade filantrópica fundada em 1942. Localizado na Rua Equador, no bairro de Santo Cristo, o prédio de sete andares do $\mathrm{H}$ ospital de O ncologia ( $\mathrm{H} \mathrm{O}$ ) foi inaugurado no dia 12 de março de 1967, porém, 0 hospital só começou a funcionar em 29 de outubro de 1973, sob a direção do médico Murilo de Castro Monte, que o conduziu até 1979.

Antes de se vincular ao IN CA, o H ospital de 0 ncologia era um órgão ligado ao IBO, que assinou um convênio de comodato com o Inamps para que o hospital começasse a funcionar. No entanto, somente em 1990, após a criação do SUS, iniciou-se a transferência do $\mathrm{H} O \mathrm{O}$ para o Instituto $\mathrm{N}$ acional de $C$ âncer, que se formalizou através da Portaria M inisterial $n-968$, de 10 de setembro de 1992 e publicada no D iário 0 ficial de 16 de setembro de 1992.

Com o novo regimento do $M$ inistério da Saúde, estabelecido pelo Decreto 2.477, de 28 de janeiro de 1998, o Hospital de O ncologia recebeu a denominação de H ospital de C âncer II do IN CA.

A primeira equipe da Seção de M astologia do $\mathrm{H}$ ospital de $\mathrm{O}$ ncologia era composta pelos médicos $\mathrm{N}$ ey Duque Estrada, $\mathrm{M}$ arcos Wajnberg, Luiz Antônio Lopes da Silveira, José Sigiliano Gomes Filho e, como chefe, J oão Luiz C ampos Soares.

\section{O Hospital Luiza Gomes de Lemos (Hospital de Câncer III do INCA)}

Em meados da década de 50, a então primeira dama do país, Sara Kubitschek, preocupada com sua mãe, a Srạ. Luíza Gomes de Lemos, procurou que ela fosse atendida pelo seu ginecologista, o Prof. Arthur Fernandes $\mathrm{C}$ ampos da Paz Filho. Pelo exame médico, o prof. Campos da Paz constatou tratar-se de um caso de câncer uterino avançado e, devido às disponibilidades terapêuticas da época, pouco havia a ser oferecido. Alguns meses depois, a Sra $\mathrm{G}$ omes de Lemos viria a falecer. Com a perda da sogra, o Presidente Juscelino Kubitschek convocou ao seu gabinete o prof. Campos da Paz, solicitando-Ihe que fizesse um planejamento para a construção de um grande hospital de cancerologia na cidade do Rio de Janeiro. Mas o professor argumentou que esta cidade já dispunha de dois excelentes hospitais especializados: 0 do Instituto N acional de Câncer e o H ospital M ário Kröeff. No entanto, ela precisava de um centro especializado em prevenção do câncer.

Assim, foi construído em 1956 e, inicialmente, operando em um prédio térreo, o Centro de Pesquisa Luíza Gomes de Lemos (CPLGL), da Fundação das Pioneiras Sociais, atendia somente casos de câncer feminino (mama e aparelho genital) e dispunha de bem montados consultórios ginecológicos, de laboratórios de citologia e histopatologia, de biblioteca, de um auditório e da Escola de Citopatologia, quetinha como objetivo formar citotecnologistas.

Porém, verificou-se a necessidade de se criar uma unidade de internação para esse centro de prevenção. Então, em 1977, foi construído, em anexo ao CPLGL, o H ospital Santa Rita, um centro detratamento de câncer ginecológico com nove andares. Em 1982, 0 conjunto hospital-ambulatórios passou a chamar-se C entro de Ginecologia Luíza Gomes de Lemos, onde se desenvolviam atividades cirúrgicas e ambulatoriais de assistência a mulheres com doenças da mama e do trato genital.

Com a extinção da Fundação das Pioneiras Sociais, em setembro de 1992, o H ospital Luíza G omes de L emos (H LGL) foi incorporado ao Instituto $\mathrm{N}$ acional de C âncer, também através da Portaria M inisterial $n$ ㅇ 968 de 10 de setembro de 1992.

Com o novo regimento do $M$ inistério da Saúde, estabelecido pelo D ecreto 2.477, de 28 de janeiro de 1998, o H ospital Luíza Gomes de Lemos recebeu a denominação de $\mathrm{H}$ ospital de $\mathrm{C}$ âncer III do INCA. 


\section{A Unificação da Mastologia no INCA}

Pela Portaria no 109, de 22 de outubro de 1992, o então Diretor Geral do IN CA, $M$ arcos Fernando de O liveira M oraes, criou "1a Comissão de Integração das U nidades Assistenciais do Instituto $\mathrm{N}$ acional de Câncer", com ênfase nas Seções de $M$ astologia. Essa comissão concluiu que não era viável a unificação naquele momento.

Já em 1997, através da Portaria n.ำ13, de 24 de janeiro, $M$ arcos $M$ oraes constituiu um Grupo de Trabalho, chefiado por Pedro Aurélio Ormonde do Carmo, para desenvolver estudos e apresentar sugestões, visando à unificação da M astologia no I N C A. 0 relatório destegrupo indicou o H LGL como a unidade capaz de englobar a unificação das Seções de M astologia das três unidades médico-hospitalares do IN CA.

Porém, essa unificação só ocorreu em 1999, por determinação do atual Diretor Geral do INCA, Jacob Kligerman, concentrando todo 0 atendimento cirúrgico e quimioterápico da mulher com câncer de mama no Hospital Luíza Gomes de Lemos, que se transformou em um dos maiores centros mundiais de tratamento deste tumor, com uma média mensal que supera 160 procedimentos mastológicos.

A unificação teve como objetivo reduzir os gastos operacionais e um obter um melhor aproveitamento dos recursos humanos e materiais, o que gerou maior produtividade e qualidade dos serviços prestados pelo Instituto. A redução do tempo médio entre a matrícula e o tratamento cirúrgico e entre este e o início da quimioterapia, a realização de tratamentos cirúrgicos ambulatoriais e 0 agendamento de consultas com hora estabelecida são exemplos da melhoria al cançada.

Porém a história da Seção de M astologia é mais do que a história de seções, hospitais ou de uma especialidade: é a história do próprio Instituto $\mathrm{N}$ acional de $\mathrm{C}$ âncer. $\mathrm{E}$ dos diretores que 0 conduziram até hoje: $M$ ario K röeff (1938/1941), Alberto Lima de M oraes Coutinho (1941/1954), Luiz C arlos de O liveira Junior (1954/1956), Antonio Pinto Vieira (1956/1962), M oacyr Alves dos Santos Silva (1962/1963 e 1972/1974), Francisco Fialho (1963/1967 e 1969/1970), J orge Sampaio de M arsillac M otta (1967/ 1969), U go de Castro Pinheiro Guimarães (1970/1972), Adayr Eiras de Araújo (1974/ 1978), João Carlos Cabral (1978), Wolfgang George Lamprecht (1978/1979), H iran Silveira Lucas (1979/1980), Ary Frauzino Pereira (1980/1985), Geraldo M attos de Sá (1985/1986), Walter Roriz de Carvalho (1986/1990), M arcos Fernando de O liveira M oraes (1990/1998) e Jacob K ligerman (desde 1998). 